\title{
Analysis of Quenching Parameters in AISI 4340 Steel by Using Design of Experiments
}

\author{
Marlon Muniz Nunes ${ }^{a} *$ E, Eduardo Miguel da Silva ${ }^{b}$, Reny Angela Renzettia \\ Tarcisio Gonçalves Brito ${ }^{a}$ \\ ${ }^{a}$ Universidade Federal de Itajubá - UNIFEI, Itabira, $M G$, Brasil \\ ${ }^{b}$ Universidade Federal de São João Del Rei - UFSJ, Santo Antônio, MG, Brasil
}

Received: April 27, 2018; Revised: August 31, 2018; Accepted: October 19, 2018

\begin{abstract}
This paper aims to investigate the effects of quenching parameters (temperature and time of austenitizing and cooling rate) on the microstructure, hardness and distortion of AISI 4340 steel by Design of Experiments (DoE). The factorial design was used to determine the influence of the factors on the response variable. After quench samples were characterized by optical and scanning electron microscopy, hardness test and dimensional analysis. Navy C-rings samples are used to determine the distortions after quenching due to development of residual stresses caused by non-uniform cooling. Results show that the cooling rate has a significant effect on the steel after quenching, however, the suitability of all factors is important to achieve the desired properties.
\end{abstract}

Keywords: quenching, design of experiments, Navy C-rings.

\section{Introduction}

Over the years, industries have begun to use different types of materials, however, steel is one of the most widely used due to its low cost $\mathrm{t}^{1}$. Steel has many engineering applications and is used in many processes involving high strain rates and high stresses ${ }^{2}$. Furthermore, steel can have its mechanical properties easily improved by heat treatment ${ }^{1}$. Among the high number of steels, AISI 4340 is widely used due to a combination of high mechanical strength, ductility and hardness. This steel is applied in tractor and airplane crankshafts, shafts with high mechanical demands and vehicles in general. The aeronautical industry uses AISI 4340 for diverse applications including tools that are applied in the aircraft manufacturing ${ }^{3}$.

Good mechanical properties are required for AISI 4340 applications so heat treatments should be taken into consideration ${ }^{2}$. The heat treatment can be used to improve machinability and formability, increase mechanical strength and restore the ductility of the material. Quenching is a commonly used heat treatment in steels to obtain desired properties in several industrial segments. In the quenching heat treatment, the steel is heated to the austenitization temperature and rapidly cooled ${ }^{4,5}$. The formation of a single-phase austenitic structure and the dissolution of carbides and other phases are the major aims of austenitizing. For this purpose, austenitizing temperature range should be high enough to homogenize the austenite and low enough avoid excessive grain growth ${ }^{6,7}$. Thus, the main parameters of the quenching process are temperature and time of austenitizing and cooling rate. The grain size is a function of austenitization temperature and time. The coarse austenite grain size may promote quenching cracks

"e-mail: marlon.emt2010@yahoo.com.br and increase the fraction of retained austenite. On the other hand, the finer austenite grain size which is obtained at lower austenitization temperatures leads to the finer martensite units which provide higher strength and toughness ${ }^{6,7}$. The most common quenching media are: mineral oils, water, aqueous solutions and salts ${ }^{4,5,8}$. The severity of a quenching media is dependent on its ability to mediate heat transfer at the hot metal interface during quenching. Its selection depends on the hardenability of the alloy and the cooling rate required to achieve the desired microstructure ${ }^{4,5}$.

During quenching process residual stresses and distortions are developed in response to non-uniform cooling and phase transformations ${ }^{8-12}$. The resulted distortions by the manufacturing processes, such as heat treatment, can increase the cost of producing a component by $20-40 \%$ where additional machining steps are required. Consequently, it is very important to predict and minimize distortions ${ }^{13,14}$. Some methods are used to evaluate and simulate the distortions promoted after quenching. The Navy C-ring has been one of the most common types of samples used to observe dimensional changes (distortion). The sample geometry with thin and thick sections prevents uniform cooling and causes phase transformation at different times that can result in residual stresses and distortions ${ }^{14,15}$. The distortion of the $\mathrm{C}$-rings is usually examined by the change in dimensions. The change in internal and external diameter and gap opening occurs by expansion and contraction of C-rings after quenching ${ }^{13}$.

In this work quenching parameters in the AISI 4340 steel were evaluated in order to verify how time and temperature of austenitization and cooling medium influence the specimen distortions and hardness. In this way, the Design of Experiments (DoE) was used to generate the experiments as well as to verify the behavior of the variables and their interactions. 
The DoE consists of three stages: pre-experimental planning, execution of the experiments and statistical analysis of the data collected. The pre-experimental planning stage is very important because in this phase the factors and their levels, as well as the response variables should be selected according to the objective of the experiment ${ }^{16}$. The experiment planning method highlight the factorial planning which allows a particular process to be studied with the realization of few experiments. The factorial designs allow engineers to determine the process factors that have significant effect on response variable and also allows to measure interactions between different factors, which make this technique an important tool for process optimization ${ }^{17}$. In this sense, the $2^{\mathrm{k}}$ factorial design was used, the procedure of this technique consists of an experiment with $k$ factors (process variables), where each parameter is tested with two levels ( -1 (minimum), +1 (maximum)) with $r$ replicates. The factorial design requires running experiments for all possible combinations of the levels of the factors. Thus, the results of such an experiment can lead to improved process yield, reduced design and development time, as well as providing reduced cost of operation ${ }^{17}$.

\section{Experimental Procedure}

The chemical composition of AISI 4340 is show in Table 1. Navy C-rings samples were obtained according to Figure 1 and submitted to a quench heat treatment with different temperatures $\left(800,850\right.$ and $\left.900{ }^{\circ} \mathrm{C}\right)$ and time $(30$, 45 and $60 \mathrm{~min}$ ) of austenitization and quenchant medium (water and oil). For microstructural characterization the samples underwent a conventional metallographic process with sectioning, hot mounting, grinding, polishing and etching with Nital. Hardness measurements (HRC - Rockwell C) were performed before and after quenching using a load of $150 \mathrm{kgf}$. The measurements of the ring dimensions were performed before and after the heat treatments by using a profile projector with an accuracy of $0.001 \mathrm{~mm}$. The gap openings were measured with a digital caliper rule with an accuracy of $0.01 \mathrm{~mm}$.

The statistical analysis was performed by software MINITAB $^{\circledR}$, the parameters were maintained at two levels, as shown in Table 2. Two center points without replicates were used, totaling ten experiments, according to Table 3. It is worth noting that the choice of these levels was only possible after the preliminary tests, which allowed to obtain the conditions for the development of the work. The choice of austenitization temperature was based on the dilatometric test, Figure 2. The sample was heated to $1300{ }^{\circ} \mathrm{C}$ at a rate of $10^{\circ} \mathrm{C} / \mathrm{min}$ to obtain the values of $\mathrm{A}_{\mathrm{cl}}\left(727^{\circ} \mathrm{C}\right)$ and $\mathrm{A}_{\mathrm{c} 3}$ $\left(764^{\circ} \mathrm{C}\right)$.

\section{Results and Discussion}

The analysis of variance (ANOVA) was used to determine the factors of the heat treating process that are affecting hardness and distortion of the steel. The results of hardness and dimension distortion obtained from the experiments are shown in Table 4. The distortion percentages were calculated by comparing the measurements before and after quench.

\subsection{Analysis of hardness}

The hardness measurements were performed in the cross section, as shown in Figure 3. The mean Rockwell C hardness measurements and its respective standard deviation are listed in Table 4. There was no significant variation of hardness between the C-rings samples. All quench processes result in an increase in the hardness value, since the sample without heat treatment has an average hardness of $31.0 \pm 1.0$ HRC. This increase in hardness was expected, rapid cooling makes it difficult to diffuse the carbon atoms thus promoting a distortion of the structure giving rise to the martensite (body-centered tetragonal structure) $)^{4,5,18}$.

Table 5 shows the analysis of variance of the hardness values, a confidence level of $95 \%$ was adopted ( $\alpha=0.05)$. Only the cooling medium showed P-value less than $5 \%$ of significance and F-value larger than Fisher's tabulated value $($ F95\% $(1,4)=7.71)$, which shows that statistically there was a difference between the cooling medium in terms of average
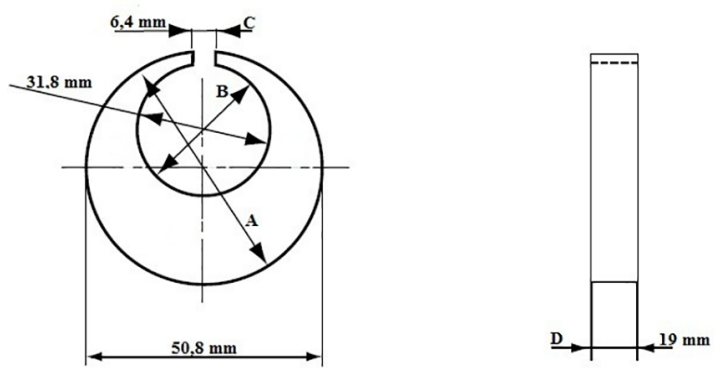

Figure 1. Navy C-rings samples: A) outside diameter; B) inner diameter; C) gap opening; D) thickness.

Table 2. Important factors and their levels.

\begin{tabular}{lcccc}
\hline & & \multicolumn{3}{c}{ Levels } \\
\cline { 3 - 5 } Factors & Unit & Low (-1) & $\mathbf{0}$ & $\begin{array}{c}\text { High } \\
(+\mathbf{1})\end{array}$ \\
\hline $\begin{array}{l}\text { Austenitizing } \\
\text { Temperature }\end{array}$ & $\left({ }^{\circ} \mathrm{C}\right)$ & 800 & 850 & 900 \\
$\begin{array}{l}\text { Soak Time } \\
\text { Quenchant Medium }\end{array}$ & min & 30 & 45 & 60 \\
\hline
\end{tabular}

Table 1. Chemical composition of the commercial AISI 4340 steel.

\begin{tabular}{lcccccccc}
\hline Element & $\mathrm{C}$ & $\mathrm{Mn}$ & $\mathrm{P}$ & $\mathrm{S}$ & $\mathrm{Si}$ & $\mathrm{Ni}$ & $\mathrm{Cr}$ \\
\hline wt. $\%$ & $0.38-0.43$ & $0.60-0.80$ & $\leq 0.030$ & $\leq 0.040$ & $0.15-0.035$ & $1.65-2.00$ & $0.70-0.90$ & $0.20-0.30$ \\
\hline
\end{tabular}


Table 3. Design of experiments plan.

\begin{tabular}{lccc}
\hline Sample & $\begin{array}{r}\text { Temp. } \\
\left({ }^{\circ} \mathrm{C}\right)\end{array}$ & $\begin{array}{c}\text { Time } \\
(\mathrm{min})\end{array}$ & Quenchant medium \\
\hline 1 & -1 & -1 & -1 \\
2 & -1 & -1 & 1 \\
3 & -1 & 1 & -1 \\
4 & -1 & 1 & 1 \\
5 & 1 & -1 & -1 \\
6 & 1 & -1 & 1 \\
7 & 1 & 1 & -1 \\
8 & 1 & 1 & 1 \\
9 & 0 & 0 & -1 \\
10 & 0 & 0 & 1 \\
\hline
\end{tabular}

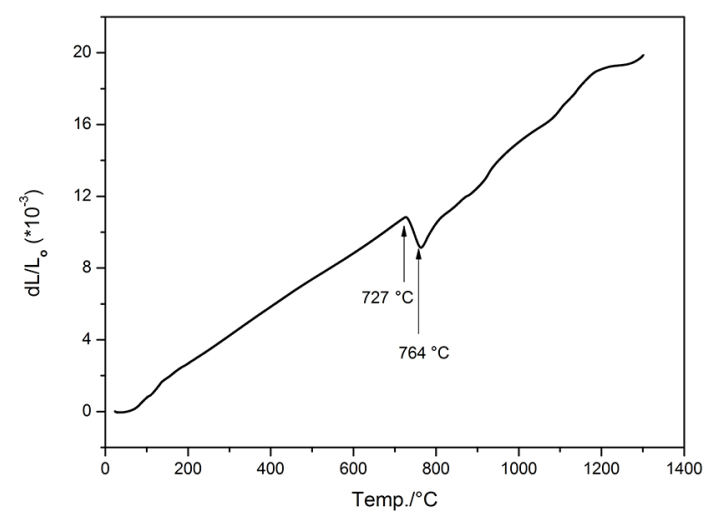

Figure 2. Dilatogram obtained after heating with a rate of $10{ }^{\circ} \mathrm{C} /$ min up to $1300^{\circ} \mathrm{C}$ of AISI 4340 steel.

Table 4. Results of hardness and percentage of distortion for heat -treated samples.

\begin{tabular}{lcccc}
\hline Sample & $\begin{array}{c}\text { Mean } \\
\text { Hardness } \\
\text { (HRC) }\end{array}$ & $\begin{array}{c}\text { Inner } \\
\text { diameter } \\
(\%)\end{array}$ & $\begin{array}{c}\text { Outside } \\
\text { diameter } \\
(\%)\end{array}$ & $\begin{array}{c}\text { Gap } \\
\text { opening } \\
(\%)\end{array}$ \\
\hline 1 & $56.2 \pm 1.0$ & 0.21 & 0.19 & 2.83 \\
2 & $54.7 \pm 0.9$ & 0.18 & 0.12 & 1.89 \\
3 & $59.1 \pm 1.2$ & 0.31 & 0.29 & 3.62 \\
4 & $53.6 \pm 1.4$ & 0.24 & 0.23 & 3.31 \\
5 & $57.3 \pm 1.1$ & 0.36 & 0.31 & 3.94 \\
6 & $55.7 \pm 0.9$ & 0.28 & 0.21 & 3.35 \\
7 & $58.4 \pm 1.0$ & 0.41 & 0.61 & 7.10 \\
8 & $57.1 \pm 1.2$ & 0.35 & 0.49 & 6.29 \\
9 & $57.4 \pm 0.6$ & 0.37 & 0.40 & 5.66 \\
10 & $55.0 \pm 0.8$ & 0.26 & 0.25 & 3.62 \\
\hline
\end{tabular}

hardness. It is also noted that there was interaction between the factors, except between time and temperature. Therefore, the suitability of all factors is important for the quenching process. The ANOVA result indicates that the model presented an excellent fit, $R^{2}$ (adj) equal to $97.56 \%$. The coefficient of determination $\left(\mathrm{R}^{2}\right)$ measures the proportion of the total

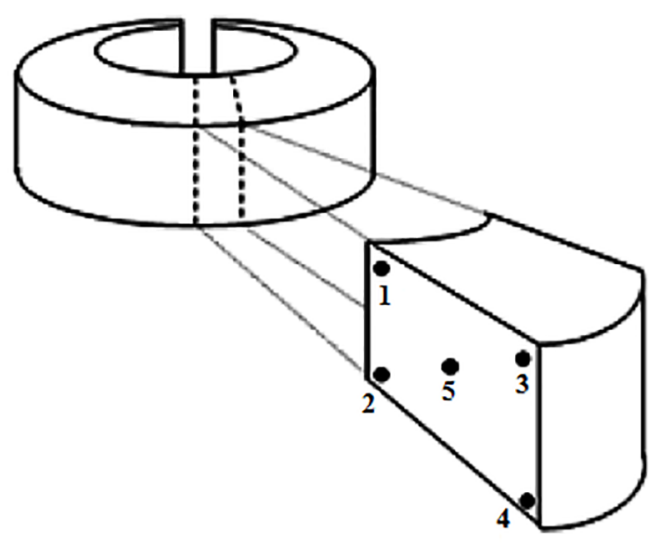

Figure 3. Location of the hardness measurements in the transversal cross-section of the quenched C-rings.

variation of the response explained by the model. Thus, the higher the $\mathrm{R}^{2}$ the lower the error and the better the model ${ }^{17}$.

The main effects for hardness as a function of temperature, time and cooling medium are shown in Figure 4. Note that with increasing temperature and soaking time there was a slight increase in the hardness. At higher austenitizing times and temperatures it is possible to dissolve a greater amount of carbides ${ }^{19,20}$. This leads to an increase in the carbon content in the formed martensite, carbon supersaturation increases the deformation of the lattice and the hardness of the material ${ }^{18,21}$. The water has higher hardening severity than oil, which generates high thermal stress in the material ${ }^{4,5}$.

The interactions plots are shown in Figure 5 and indicate that the one factor has impact on other factors. Figure 5 (a) shows that hardness increased with higher temperature and water. It is also observed that temperature had a greater effect on hardness when the oil was used. When the samples were cooled in water the variation of austenitization temperature had little influence on the hardness. Figure 5 (b) depicts the effect of time and quenchant medium on hardness. It is observed that greater hardness was achieved by using long time and water. When the C-rings were cooled in oil the average hardness practically did not change, regardless of the time used.

\subsection{Dimensional analysis of samples Navy C-rings}

According to the percentage of distortion after heat treatment, Table 4, all samples had their dimensions increased. A high distortion was observed in the gap opening, such behavior was also observed in other works ${ }^{9,22}$. The final gap opening and outer diameter of the Navy C-ring are associated with martensite formation in the thicker portion of the specimen. The formation of martensite results in a volumetric expansion of the material ${ }^{22}$. 
Table 5. Analysis of variance (ANOVA): Hardness.

\begin{tabular}{lccccc}
\hline Source & DF & Adj. SS & Adj. MS & F & P \\
\hline Temperature & 1 & 3.0012 & 0.0980 & 1.48 & 0.290 \\
Time & 1 & 2.3112 & 0.0249 & 0.38 & 0.572 \\
Quenchant & 1 & 18.0075 & 0.9816 & 14.86 & 0.018 \\
Temperature*Time & 1 & 0.0612 & 0.0613 & 0.93 & 0.390 \\
Temperature*Quenchant & 1 & 2.1012 & 0.9680 & 14.66 & 0.019 \\
Time*Quenchant & 1 & 1.7113 & 2.5423 & 38.50 & 0.003 \\
Temperature*Time*Quenchant & 1 & 2.3112 & 2.3112 & 35.00 & 0.004 \\
Error & 4 & 0.2642 & 0.0660 & & \\
Total & 11 & 29.7692 & & & \\
\hline $\mathrm{R}^{2}$ (Adj) & & & & \\
\hline
\end{tabular}

*Fisher distribution: F95\% $(1,4)=7.71$.

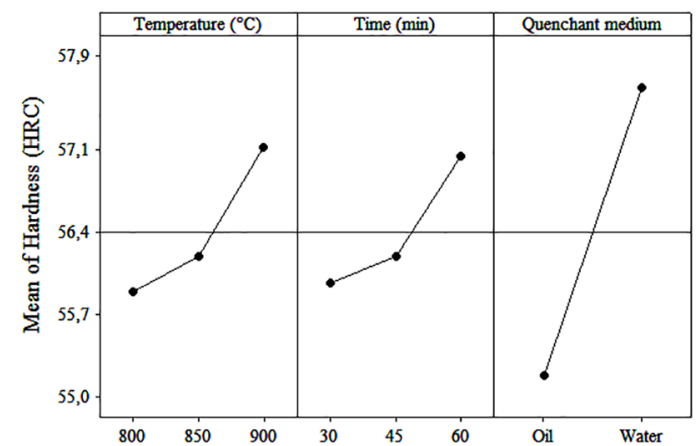

Figure 4. Main effects plot (data means) for Hardness (HRC).

The analysis of variance was performed and the effects of the factors on the gap opening percentage were evaluated as shown in Table 6. Note that none of the factors had significant effects. The ANOVA result indicates that the model presented a good fit, $\mathrm{R}^{2}$ (adj) equal to $77.23 \%$. The main effects, Figure 6, allowed to evaluate the influence of each factor on the measured distortion. The percentage of average distortion increased when the cooling medium used was water. This behavior was expected, since low-viscosity fluids promote higher heat transfer rates and, consequently, larger distortion due to non-uniform temperature distribution ${ }^{5,9}$. It is noted that an increase in the temperature and time results in an increase in the percentage of distortion. High temperatures and long holding time lead to an increase in the solubilization of the carbides, increasing the distortion. In addition, increasing the austenitization temperature the thermal gradient between the sections of the austenitized piece at $900{ }^{\circ} \mathrm{C}$ was higher when compared to samples heated to $800^{\circ} \mathrm{C}$.

\subsection{Microstructural characterization}

Microscopic examination is an extremely useful tool in the study and characterization of materials. The structural characterization allows to obtain qualitative information, observation of the morphology and homogeneity of the structures, as well as quantitative, measure the volumetric fraction of the present phases and distribution and size of the grain in the microstructure. The study of the microstructure is also useful to predict the mechanical properties of alloys and to show if an alloy was correctly heat treated ${ }^{23}$. a)

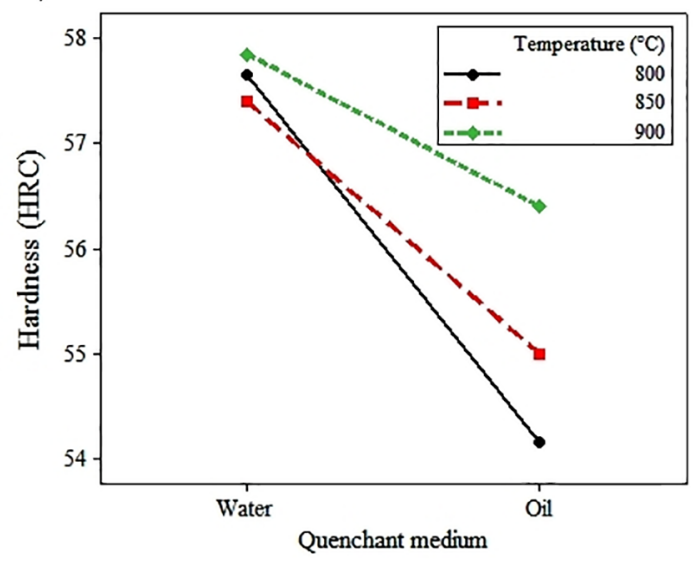

b)

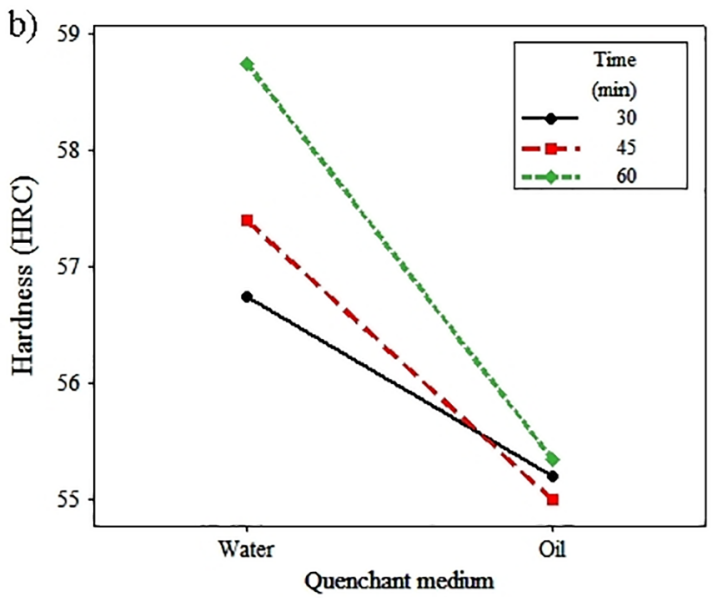

Figure 5. Interaction between: a) quenchant and temperature; b) quenchant and time for hardness 
Table 6. Analysis of variance (ANOVA): Distortion gap opening.

\begin{tabular}{lccccc}
\hline Source & DF & Adj. SS & Adj. MS & F & P \\
\hline Temperature & 1 & 10.1926 & 0.0871 & 0.16 & 0.712 \\
Time & 1 & 8.6320 & 1.4410 & 2.60 & 0.182 \\
Quenchant & 1 & 3.7744 & 0.0933 & 0.17 & 0.703 \\
Temperature*Time & 1 & 1.8915 & 1.8915 & 3.41 & 0.139 \\
Temperature*Quenchant & 1 & 0.0028 & 0.0720 & 0.13 & 0.737 \\
Time*Quenchant & 1 & 0.0210 & 0.0952 & 0.17 & 0.700 \\
Temperature*Time*Quenchant & 1 & 0.0903 & 0.0903 & 0.16 & 0.707 \\
Error & 4 & 2.2210 & 0.5553 & & \\
Total & 11 & 26.8257 & & & \\
\hline R $^{2}$ (Adj) & & & & \\
\hline
\end{tabular}

*Fisher distribution: F95\% $(1,4)=7.71$.

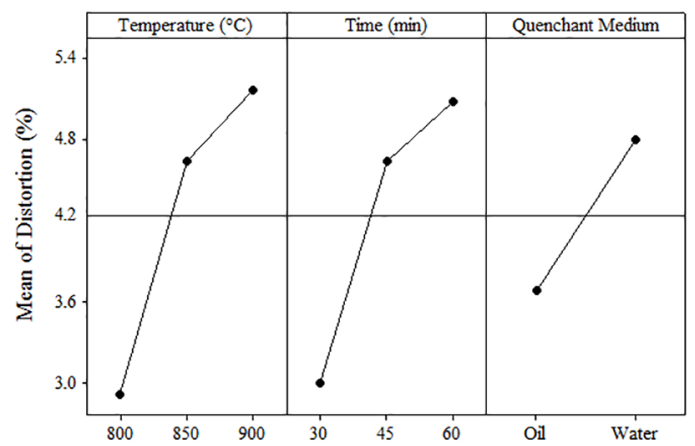

Figure 6. Main effects plot (data means) for Distortion (\%).

The AISI 4340 steel has high hardenability, so it is expected that all the analyzed samples present the martensitic phase. The micrographs, Figure 7, show darkening of the martensitic structure. Note that there was no significant difference between the samples cooled in water and oil. The two-cooling media had a sufficient heat extraction rate to form martensite. Based on the thermal treatments performed, the presence of the ferrite structure is not expected, but the white regions may present retained austenite and ferrite. SEM observation shows that both the sample heated at $800{ }^{\circ} \mathrm{C}$ (Fig. 8 (a)) and the sample heated at $900{ }^{\circ} \mathrm{C}$ (Fig. 8 (b)) showed microstructure with a lath appearance, being this characteristic aspect of the martensitic microstructure.

\section{Conclusions}

The use of the experiment planning plan allowed to evaluate the effect of the austenitization temperature, soaking time and cooling medium on hardness and the distortion of the C-rings. The models showed good adjustments, $\mathrm{R}^{2}$ (adj) equal to $97.56 \%$ for hardness and $77.23 \%$ for distortion. The analysis of the interactions between the parameters was shown to be an important element for the control of the quenching process, evidencing that the joint action of parameters with little influence on hardness can lead to significant effects. The hardness increases with the homogenization of austenite and the distortion increases with increasing austenitizing temperature and time. The cooling medium was the only parameter that showed a significant effect on hardness
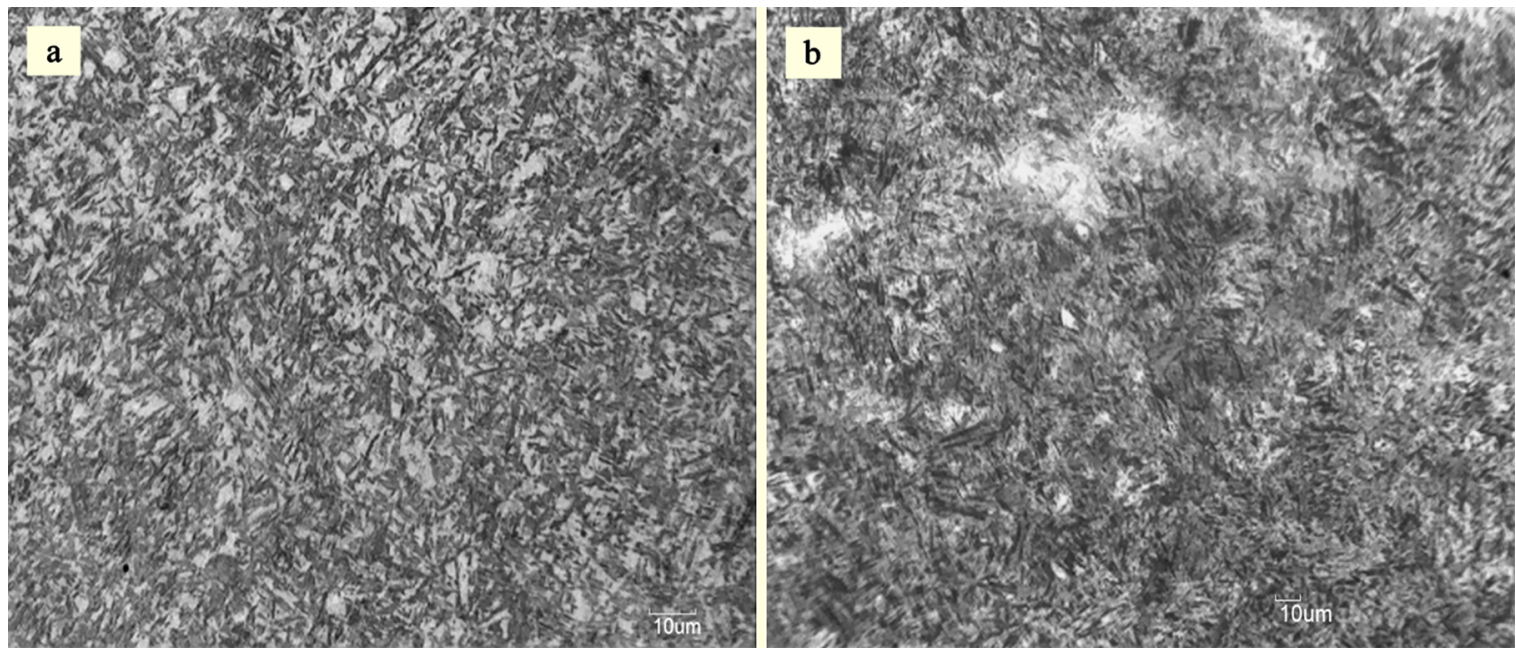

Figure 7. Optical micrographs of AISI 4340 steel austenitized at $800^{\circ} \mathrm{C}$ for 30 minutes cooled in: (a) water and (b) oil (magnification $200 x$ ). 

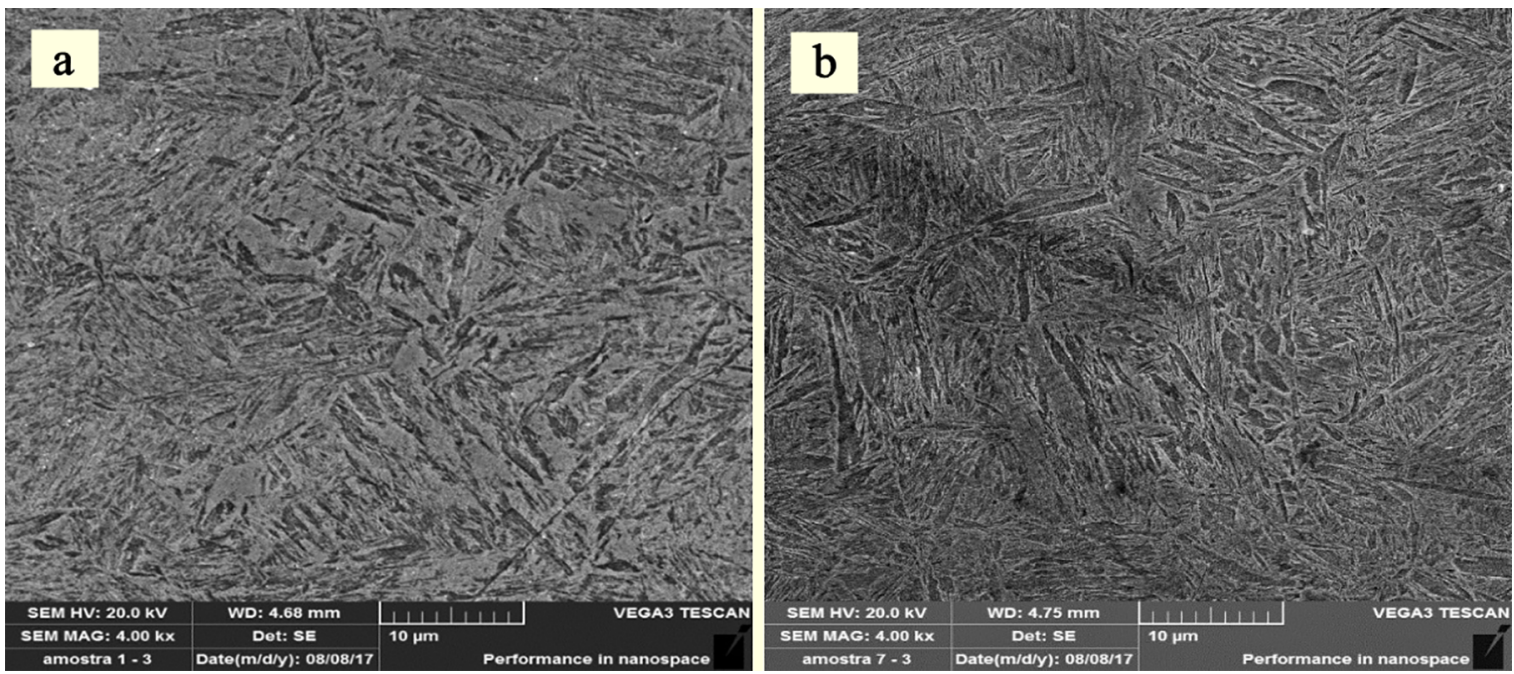

Figure 8. SEM observation of AISI 4340 steel cooled in water after the heat treatment: (a) $800{ }^{\circ} \mathrm{C}$ for 30 minutes and (b) $900{ }^{\circ} \mathrm{C}$ for 60 minutes.

value, being thus one of the most important parameters of the quenching process. The use of oil as a cooling medium for the quenching process of AISI 4340 steel has shown to be more indicated, quenched samples in this medium had high hardness and a lower percentage of distortion.

\section{Acknowledgements}

The authors of this work would like to thank the financial support by the Brazilian agency CAPES.

\section{References}

1. Van Vlack LH. Elements of Materials Science and Engineering. 6th ed. New York: Pearson Education; 1989. 610 p.

2. Boakye-Yiadom S, Bassim MN. Effect of prior heat treatment on the dynamic impact behavior of 4340 steel and formation of adiabatic shear bands. Materials Science and Engineering: A. 2011;528(29-30):8700-8708.

3. Torres MAS, Voorwald HJC. An evaluation of shot peening, residual stress and stress relaxation on the fatigue life of AISI 4340 steel. International Journal of Fatigue. 2002;24(8):877-886.

4. Totten GE. Steel Heat Treatment: Metallurgy and Technologies. 2nd ed. Boca Raton: CRC Press; 2006. 848 p.

5. ASM International. ASM Metals Handbook. Volume 4. Heat Treating. 10th ed. Materials Park: ASM International; 1991.

6. Tavares SSM, Pardal JM, Martins TRB, Schmitt VM, Szlejf JFV. Influence of Austenitizing on the Mechanical Properties of Maraging 300 and Sae 4340 Steels - Comparative Study. Materials Research. 2017;20(Suppl 2):39-46.

7. Mirzaee M, Momeni A, Aieni N, Keshmiri H. Effect of quenching and tempering on microstructure and mechanical properties of 410 and $410 \mathrm{Ni}$ martensitic stainless steels. Journal of Materials Research. 2017;32(3):687-696.
8. Mackerle J. Finite element analysis and simulation of quenching and other heat treatment processes: A bibliography (1976-2001). Computational Materials Science. 2003;27(3):313-332.

9. Civera C, Rivolta B, Simencio-Otero RL, Lúcio JG, Totten GE, Canale LC. Vegetable Oils as Quenchants for Steels: Residual Stresses and Dimensional Changes. Materials Performance and Characterization. 2014;3(4):306-325.

10. Grum J, Božič S, Zupančič M. Influence of quenching agents on distortion of modified navy-c rings made of heat-treatment steel 4140. In: Proceedings of the $8^{\text {th }}$ Seminar of the International Federation for Heat Treatment and Surface Engineering ; 2001 Sep 12-14; Dubrovnik- Cavtat, Croatia; 2001. p. 145-155.

11. Bhadeshia HKDH, Honeycombe R. Steels: Microstructure and Properties. 3rd ed. Oxford: Butterworth-Heinemann; 2006, 360 p.

12. Canale LCF, Totten GE. Quenching technology: a selected overview of the current state-of-the-art. Materials Research. 2005;8(4):461-467.

13. Manivannan M, Northwood DO, Stoilov V. Use of Navy C-rings to study and predict distortion in heat treated components: experimental measurements and computer modeling. International Heat Treatment and Surface Engineering. 2014;8(4):168-175.

14. Brooks BE, Beckermann C. Prediction of heat treatment distortion of cast steel c-rings. Proceedings of the 61st SFSA Technical and Operating Conference. Chicago: Steel Founders Society of America; 2007. p. 1-30.

15. Li J, Feng Y, Zhang H, Min N, Wu X. Thermomechanical Analysis of Deep Cryogenic Treatment of Navy C-Ring Specimen. Journal of Materials Engineering and Performance. 2014;23(12):4237-4250.

16. Farooq MA, Nóvoa H, Araújo A, Tavares SMO. An innovative approach for planning and execution of pre-experimental runs for Design of Experiments. European Research on Management and Business Economics. 2016;22(3):155-161. 
17. Montgomery DC, Runger GC. Applied Statistics and Probability for Engineers. 5th ed. New York: John Wiley \& Sons; 2010. 784 p.

18. Reed-Hill RE. Physical Metallurgy Principles. 2nd ed. New York: Van Nostrand; 1973. 920 p.

19. Jiang B, Wu M, Zhang M, Zhao F, Zhao Z, Liu Y. Microstructural characterization, strengthening and toughening mechanisms of a quenched and tempered steel: Effect of heat treatment parameters. Materials Science and Engineering: A. 2017;707:306-314.

20. Feng YY, Xu C, Su X, Sun YL, Pan X, Cao YD, et al. Influence of austenization temperature on microstructure and mechanical properties of a new ultra-high strength low alloyed steel. Materials Testing. 2017;59(11-12):990-996.
21. Dieter GE. Mechanical Metallurgy. 3rd ed. New York: McGrawHill; 1986. 800 p.

22. da Silva AD, Pedrosa TA, Gonzalez-Mendez JL, Jiang X, Cetlin PR, Altan T. Distortion in quenching an AISI 4140 C-ring - Predictions and experiments. Materials \& Design. 2012;42:55-61.

23. Leng Y. Materials Characterization: Introduction to Microscopic and Spectroscopic Methods. Singapore: John Wiley \& Sons; 2008. 337 p. 